\title{
CONTRASTES DE LUZ Y SOMBRA EN EL CARIBE COSTARRICENSE. RECONSTRUCCIÓN DEL PAISAJE LIMONENSE DESDE LOS RELATOS DE VIDA
}

\section{CONTRASTS OF LIGHT AND SHADOW ON THE COSTA RICAN CARIBBEAN. RECONSTRUCTION ON LIMON'S LANDSCAPE FROM LIFE STORIES}

\section{Pablo Carballo Chaves*}

\author{
RESUMEN
}

Desde una aproximación de la reflexión teórica del paisaje en relación con lo cultural y el turismo y desde la metodología del relato de vida, este artículo profundiza en las miradas que tienen tres relatores sobre las modificaciones y la reconstrucción cultural que ha sucedido en Limón. Se parte de la recomendación de los relatos de vida de rescatar los recuerdos y significados por espacios de vida: niñez, juventud y adultez/vejez. En la niñez se evidencia una añoranza sobre lo colorido de ese pasado recordado. En la juventud se hace una comparación entre la introducción en el mundo laboral y las nuevas relaciones que se empiezan a vivir. En la adultez/vejez, que es donde se encuentran los tres relatores, se da una interpretación desde los cambios que han ocurrido, profundizando en sus miradas del paisaje como énfasis analítico.

PALABRAS CLAVE: COSTA RICA * PAISAJE * TURISMO * HISTORIA * CULTURA

\section{ABSTRACT}

Approaching from a landscape theoretical reflection we analyse culture and tourism from life story methodology. This article explores three different views rapporteurs on change and cultural reconstruction that has happened in Limon. Based on life stories methodology we rescue memories and meanings involving childhood, youth, and old age. In childhood a longing on the colorful past that is remembered. In a comparison of youth entering the workforce and new relationships. In adulthood/old age, which is where the three rapporteurs are at the moment, an interpretation is given from the changes that have occurred in their lives, deepened in a landscape analytical emphasis.

KEYWORDS: COSTA RICA* LANDSCAPE * TOURISM * HISTORY * CULTURE

Escuela de Sociología de la Universidad de Costa Rica (UCR) y Cátedra de Ciencias Sociales y Humanidades de la Universidad Estatal a Distancia (UNED-Costa Rica). 


\section{INTRODUCCIÓN Y REFLEXIÓN METODOLÓGICA}

Este artículo se presenta como parte de los resultados del proyecto Centros Históricos del Turismo ${ }^{1}$ realizado en la Universidad de Costa Rica. Después de haber hecho una serie de reflexiones de carácter principalmente cuantitativo para la elaboración de anteriores productos de investigación, en este momento la actual fase procura una profundización cualitativa en el estudio del turismo en le región del Caribe, específicamente en el centro de la provincia ${ }^{2}$ y superando la delimitación metódica anterior, que consistió en trabajar en el barrio Pacuare $^{3}$. Los intereses se concentran ahora en reconstruir el paisaje de la provincia, para lo cual se utilizó la combinación de referentes teóricos del paisaje, así como también las ventajas metodológicas del uso de entrevistas para rescatar los relatos que las personas tienen de su contexto paisajístico.

Es bajo esta idea general que se busca rescatar las expresiones, ideas y opiniones, relatos en un sentido técnico-metodológico, que las $y$ los pobladores de la provincia valoran en su dimensión de escenarios de vida. Con el objeto de poder seleccionar un grupo de personas que brindaran información de pertinencia para el proyecto $y$ en particular para la fase de investigación, inicialmente se propuso y construyó una clasificación de ejes en los que interesaba profundizar dicha reconstrucción de paisajes. Estos ejes fueron enmarcados en las siguientes categorías: a) Transporte, b) Mercado, c) Recreación y d) Etnicidad. Esto debido a lo amplio y los múltiples elementos que alberga el escenario socio-cultural de la región. Una vez categorizados los cuatro ejes generales de estudio del proyecto, las y los diferentes miembros del proyecto se adjudicaron un eje para desarrollar

1 Proyecto adscrito a la Vicerrectoría de Investigación de la Universidad de Costa Rica. Número de inscripción: 211-B0-246.

Hay que recordar que el proyecto involucra áreas específicas tanto de Limón (Barrio Central: Pacuare), como barrios en Puntarenas (Barrios: Juanito Mora y El Carmen), véase: Carballo, 2013.

Esto porque se construyó y llevó a cabo un censo, que ameritaba la delimitación territorial y poblacional en la fase anterior. cada uno. En el presente escrito se expone el punto sobre Etnicidad o étnico.

Una vez hecha esta primera reflexión de los elementos paisajísticos y una distribución de los ejes según los integrantes, se procedió a generar un listado de posibles candidatos y candidatas para ser entrevistados. Se entrevistó finalmente a un mínimo de tres personas por eje, con el fin de poder tener la posibilidad de contraste de sus relatos. Además, el tiempo de preparación de logística y elaboración de las entrevistas se desarrolló entre febrero hasta julio del año 2013, divido en los primeros 3 meses en construcción de ejes y búsqueda de posibles entrevistados, $y$ en el segundo trimestre en la realización de las entrevistas y transcripciones, que eventualmente quedaron culminadas a mediados de agosto de 2013.

\section{EL USO DE LA TÉCNICA DEL RELATO DE VIDA}

El recurso de la entrevista es fundamental para lograr información pertinente, sin embargo, el interés es conseguir recabar los relatos de vida de las personas que se entrevistaron. La justificación del empleo de los relatos de vida radica en que, mientras la entrevista es más cerrada en la mirada, el relato de vida se considera una herramienta que tiene por fundamento hacer un recorrido por el itinerario biográfico de las personas buscando entresacar dimensiones particulares, sean trabajo, lucha social, vida cotidiana, entre otros. Además de poder ubicar dichos escenarios con otras categorías biográficas, como infancia, juventud, vida adulta, etc. (cfr. Bertaux, 2005). En este sentido, lo que se busca es entrar al mundo de las personas, a su mesocosmos, como lo señala el autor:

... la hipótesis central de la perspectiva etnosociológica es que las lógicas que rigen el conjunto del mundo social o mesocosmos se dan igualmente en cada uno de los microcosmos que lo componen: observando uno solo, o mejor varios de esos microcosmos, $y$ por poco que se logre identificar las lógicas de acción, los mecanismos sociales, los procesos de reproducción y de transformación, se deberían captar al menos algunas de las 
lógicas sociales del mesocosmos mismo (Bertaux, 2005: 18).

Se apela a la fuerza de lo que se puede contar, es decir relatar, como señala Alasdair MacIntyre:

... la unidad de una vida humana es la unidad de una búsqueda relatada. En ocasiones, las búsquedas fracasan, se frustran, son abandonadas o se pierden en distracciones, $y$ las vidas humanas también se pierden de la misma manera. Pero los únicos criterios de éxito o fracaso de la vida humana como un todo son los criterios de éxito o fracaso de una búsqueda relatada o relatable (MacIntyre citado en Touraine, 2006: 186-187).

Aunque la idea no es concentrarse en el éxito o fracaso a nivel de lo que cuentan, son los criterios que legitiman y son referidos los que en una modalidad de relato dan consistencia o justificación a los procesos — visibles o no. En este sentido, la técnica del relato es un aporte en la búsqueda de nuevos espacios y material analizable, sobre lo que ya Max Weber (2008) señalaba en el "sentido mentado"4 que las personas atribuyen a lo que hacen.

Lo que permite esta técnica es la posibilidad de ahondar en el relato, en tanto que "un testimonio de la experiencia vivida, pero es un testimonio orientado por la intención de conocer del investigador que lo recoge" (Bertaux, 2005: 51). De esta manera, las intenciones son de carácter reconstructivo del paisaje en relación con el trabajo, como más adelante se explica en la teoría y que tiene un importante entronque con las condiciones de esos

$4 \quad$ Aunque M. Weber habla del "sentido mentado", se posiciona desde una racionalidad que señala que la persona podría saber qué es lo que está haciendo o al menos tener una cierta claridad. Sin embargo, este punto es debatible a la luz de las diferentes reflexiones críticas sobre la racionalidad y sobre el factor inconsciente. Sin embargo, lo que se busca retomar de Weber es su aporte desde el sentido que se le da o se le intenta dar (haciendo esfuerzos de reconstrucción, que es el aporte del relato). países vividos en sus experiencias cotidianas y ahora relatadas.

\section{DESCRIPCIÓN DE LAS ENTREVISTADAS Y EL ENTREVISTADO (MATRIZ DE ANÁLISIS)}

Como se señaló, el eje de desarrollo es el étnico, por lo que amerita una definición, aunque breve $y$ en alguna medida incompleta, pero puntual para ubicar la reflexión y la justificación de la categoría y de las personas seleccionadas. Así, etnicidad se entiende específicamente:

... cuando un grupo humano, por haber cristalizado como grupo étnico en el transcurso de un proceso histórico en el que sus miembros han participado de una experiencia colectiva básicamente común, posee una serie de elementos culturales específicos que actúan como marcadores de su diferencia objetivo respecto de otros grupos, es decir, como marcadores de su específica identidad (Moreno, 1985: 13).

Esta forma de presentar una conceptualización sobre la etnicidad permite, aunque sea sucintamente, orientar la justificación de las personas seleccionadas, así como un grupo de preguntas que componen la matriz de interrogación. Además, muestra una dimensión culturalmente evidente, pero donde diferentes matices juegan fundamental importancia en la construcción de sentido sobre diferentes eventos, actos y por supuesto, el paisaje.

Por esa razón, se entrevistaron tres personas que fueran parte de diferente contexto étnico/cultural en la provincia de Limón. Es significativo recordar que en el marco del proyecto ampliado (Limón y Puntarenas), el total de relatos de vida hechos fueron de 21 relatos correspondientes con 7 miembros del proyecto (3 por investigador), donde 12 de esos relatos fueron para la provincia de Limón. Esto con la intención de tener relatos para las diferentes dimensiones y que también pueden a la vez, de acuerdo a la profundidad de las reflexiones, ser utilizadas para complementar de manera intraejes. En este sentido, si bien es cierto para esta 
reflexión la base son 3 relatos, se cuenta con un material extendido para dar mayor profundidad a ciertos temas cuando dicho material permita complementar.

Debido a la presencia histórica fuerte de la población afrodescendiente $y$ de las comunidades chinas ${ }^{5}$ en la provincia, dos personas fueron seleccionadas $y$ entrevistadas respondiendo a dicho contexto. Una tercera persona a la que se le aplicó el relato se denomina como "blanca" y se mantiene la categoría por razones de análisis. Otro elemento importante era tener relatos tanto de un hombre como de alguna mujer, y se logró entrevistar a dos mujeres y un hombre. En el cuadro 1 se aprecian características puntuales de las personas.

\section{CUADRO 1 \\ CARACTERÍSTICAS SOCIO-CULTURALES DE LOS INFORMANTES 2013}

\begin{tabular}{lccc}
\hline \multicolumn{1}{c}{ ELEMENTOS } & RELATO A & RELATO B & RELATO C \\
& JOYCELIN SAWYERS & ARABELLA SALAVERRY & OSCAR ZEN \\
\hline Consideración étnica & Afrodescendiente & "Blanca" & China-Mandarín \\
Espacio laboral & Docencia y Política & Arte & Comercio e inversión \\
Ocupación & Docente/política & Actriz/escritora & Ingeniero/Empresario \\
Edad & En los setenta & En los sesenta & En los sesenta \\
Infancia & Limón & Limón & China \\
Juventud-adultez & Limón & San José-Exterior & Limón \\
Vive actualmente & Limón & San José & Limón \\
\hline
\end{tabular}

Fuente: Elaboración propia a partir de la información de las personas consultadas.

La diversidad de espacios de vida permite mostrar reflexiones sobre los intereses propios de las personas, pero permiten valorar cambios para unos, pero no necesariamente para otros. Se habla de que la forma étnica apropiada en las personas permite generar formas de ver $y$ aproximarse al entorno, así como incidir en el paisaje. Retomando la idea teórico/metodo- lógica del relato se optó por dividir la reconstrucción según etapas de vida (niñez/juventud/ adultez-vejez) con el fin de valorar contrastando los cambios y modificaciones sustanciales de las personas en dichos procesos de impacto paisajístico. El cuadro 2 muestra la codificación de los criterios de interés según la dimensión de etapas de vida.

$5 \quad$ Existe una pluralidad de expresiones culturales a lo interno de la población migrante china. En este caso, se podría hablar de una dicotomía básica a partir del factor idiomático, donde unos hablan mandarín y otros cantones. 


\section{CUADRO 2 \\ MATRIZ ANALÍTICA DE LOS RELATOS DESDE EL EJE ÉTNICO 2013}

\begin{tabular}{|c|c|c|c|c|c|}
\hline RELATORES & $\begin{array}{l}\text { DIVISIÓN DE } \\
\text { LOS RELATOS }\end{array}$ & $\begin{array}{l}\text { CONST. } \\
\text { IDENTIDAD } \\
\text { CULTURAL Y } \\
\text { PAISAJE }\end{array}$ & $\begin{array}{l}\text { IMPACTO EN LA } \\
\text { NATURALEZA }\end{array}$ & $\begin{array}{l}\text { TRABAJO/ } \\
\text { TURISMO }\end{array}$ & $\begin{array}{l}\text { REL. CON SAN } \\
\text { JOSÉ }\end{array}$ \\
\hline J. Sawyers & $\begin{array}{c}\text { Niñez } \\
\text { Juventud }\end{array}$ & & \multirow{3}{*}{$\begin{array}{l}\text { Modificaciones } \\
\text { en el transcurso } \\
\text { histórico de lo } \\
\text { cultural y lo } \\
\text { natural. }\end{array}$} & \multirow{3}{*}{$\begin{array}{c}\text { Vinculación } \\
\text { histórica entre } \\
\text { turismo, trabajo y } \\
\text { paisaje. }\end{array}$} & \multirow{3}{*}{$\begin{array}{c}\text { Vinculaciones } \\
\text { históricas entre } \\
\text { las provincias de } \\
\text { San José y Limón. }\end{array}$} \\
\hline A. Salaverry & $\begin{array}{l}\text { Adultez/vejez } \\
\text { Niñez } \\
\text { Juventud } \\
\text { Adultez/vejez }\end{array}$ & $\begin{array}{c}\text { Elementos que } \\
\text { identifiquen } \\
\text { comportamientos } \\
\text { y patrones de } \\
\text { diferenciación } \\
\text { y vivencia del } \\
\text { paisaje. }\end{array}$ & & & \\
\hline O. Zen & $\begin{array}{c}\text { Niñez } \\
\text { Juventud } \\
\text { Adultez/vejez }\end{array}$ & & & & \\
\hline
\end{tabular}

Fuente: Elaboración propia según la técnica del relato de vida.

Esta matriz busca clarificar por un lado, los componentes en reconstrucción: identidad cultural (altamente volátil), los cambios naturales específicos, la vinculación entre el trabajo $y$ el turismo, $y$ el papel del referente provincial de San José. Por otro lado, reconstruye estos elementos en el proceso de crecimiento $y$ envejecimiento de la persona. Esto tiene como principal aporte la asimilación o posible reflexión de razones subjetivas de cambio, así como, la vivencia de dichos cambios. Este último factor es fundamental, ya que el paisaje, como se verá en la teoría, por distintas razones, es un factor social que también se vive y experimenta, así como tiene un componente fundamental en la construcción social e individual de las personas.

\section{CONSIDERACIONES TEÓRICAS SOBRE LA CONSTRUCCIÓN PAISAJÍSTICA}

En los últimos 30 años, las reflexiones sobre el paisaje han tenido un importante aporte en la comprensión de las relaciones entre el ser humano y su entorno ambiental/natural. Sin embargo, la reflexión tiene antecedentes mucho más antiguos, donde se hace énfasis en el condicionante que tiene el entorno en las formas de organización de las personas y en sus estilos de pensamiento. Esta idea es parte de lo que el filósofo japonés Tetsuro Watsuji (2006) argumentaba en sus distintas reflexiones ${ }^{6}$. Este autor, a partir de una perspectiva basada en una visión filosófica de raigambre heideggeriana - desde la existencia en relación con el ser ${ }^{7}$ propone que es el entorno, uno de los factores fundamentales para comprender como se interioriza la subjetividad de las personas y en la articulación de su vivencia socio-ambiental como se construyen patrones religiosos y en general, culturales. Siendo precisamente la relación condicionante del ambiente climático un desencadenante (no necesariamente absoluto, ni único) de la construcción cultural.

6 T. Watsuji analiza desde las décadas del veinte al cuarenta del siglo $\mathrm{xx}$

7 De manera reducida, por razones diversas, la propuesta de Martin Heidegger se articula desde la idea de la existencia humana, desde la reflexión del dasein ("ser ahí"), donde el ser parte del mundo y sus condicionantes articulan la existencia y esto se da en el tiempo, en un espacio lapso que ocurren las cosas (Heidegger, 2002 y Savater, 2011). T. Watsuji incorpora a la reflexión el tema del lugar y de ahí su interés por el tema del paisaje. 
Si bien, Watsuji llega a proponer diferentes ideas, criticables en diferente medida, en aras a la reflexión sociológica aquí pertinente, interesa rescatar que efectivamente el ambiente, en tanto que una dinámica paisajística vivida, interviene $y$ condiciona lo que pensamos $y$ hacemos en nuestras relaciones, que a su vez son llevadas a cabo en el ambiente/paisaje y eventualmente también llega a ser modificado. Modificado en un sentido de potenciar o inclusive, modificado en un sentido contrario a la organización climática/ambiental inicial ${ }^{8}$. Se tiene así una idea o lógicas de pensamiento que desde inicios del siglo xx empieza a desarrollarse $y$ en conjunto con el desarrollo de las ciencias sociales $y$ las reflexiones interpretativas, surge un escenario de investigación que recupera la relación ser humano, relaciones sociales y vinculación paisajística.

La Antropología y la Sociología con el tiempo fueron fortaleciendo el análisis de esta relación que se ha mostrado cada vez más estrecha $y$ dependiendo de los linderos teóricos se profundiza en determinada línea de reflexión. Un elemento que ha tenido una particular preocupación de estudio es cómo el trabajo - las prácticas humanas de producción y reproducción-, interviene $y$ modifica el ambiente $y$ por lo tanto, el paisaje. Este factor es fundamental en la comprensión del impacto de la vida de las personas y su vida social, alterando y ajustando su entorno biótico en favor de una apropiación en buena medida inconsciente de su exterioridad. El caso de la construcción de la agricultura es un ejemplo de este fenómeno, donde converge la adaptación de los espacios naturales para el consumo, dándoles criterios artificiales. Esto incentiva la reflexión desde esa perspectiva analítica.

Dentro de la reflexión sobre el paisaje surgen diferentes problemas de índole analítico. Entre ellos la relación entre paisaje y arte, donde el concepto paisaje ha estado asociado con la capacidad de un creador de dicho paisaje en sentido artístico (Roger, 2007). No obstante, en

8 Un ejemplo de esta modificación climática sería el calentamiento global — por el efecto de los gases de invernadero-, donde los climas se ven modificados por la acción humana, infringiendo una alteración ulterior del clima y por ende, del paisaje. este estudio se buscan capacidades o miradas paisajísticas de aquellas personas que los disfrutan, ya sea que están conscientes o no de su participación en su construcción. El énfasis en esta reflexión de los discursos es la potencialidad de las miradas paisajísticas desde el eje étnico-cultural o socio-cultural en las interpretaciones de dichos paisajes y su valoración.

\section{EL TRABAJO COMO ELEMENTO CONDICIONANTE DE LA CONSTRUCCIÓN SOCIAL}

Un factor importante que está dentro de los ejes de reflexión sociológica, es la interacción seres humanos y naturaleza. Si bien, tal vez no ha sido un eje central en la discusión de la disciplina, en corrientes más contemporáneas el debate ha alcanzado un significativo interés $y$ aporte. Un eje de este debate ha sido la construcción del ambiente a partir de necesidades humanas y sociales. Desde una línea de división de la sociedad, se señala que:

Las clases y grupos sociales que se estructuran en el marco del modo de producción son los que socialmente modelan el paisaje. Por una parte los grupos dominantes, darán forma a sus proyectos económicos, bajo modalidad de 'planes de desarrollo', que serán sus propuestas de políticas para agenciar sus intereses económicos. En otras palabras, los nuevos ejes de acumulación se materializan mediante políticas de desarrollo y la actividad económica como tal (Cordero, 2012: 4-5).

Esta idea, fundamentada en el marxismo, establece tres elementos importantes: 1) las personas modifican el paisaje, pero lo hacen en colectividades, grupos, clases, etc.; 2) el paisaje entra dentro de la disputa y conflicto social, y no se distancia de los resultados de los consensos o disensos existentes en la sociedad; 3) el consenso también puede pasar a conformarse como política nacional, lo que llega a impactar más allá de comunidades, sino a sistemas sociales más extensos y complejos, que tienen una importante $y$ determinante relación biótica con el entorno natural. 
Así, estos 3 puntos orientan en distinguir que la modificación, además de ser doble, al llegar a ser parte de una lógica de política nacional, se prescribe como legítima y necesaria. Se dice doble, porque la modificación es tanto del ser humano modificando el entorno, como nosotros siendo modificados a su vez por este (Watsuji, 2006). Interesa profundizar en la primera relación, en el proceso de ajuste ambiental, determinado por las condiciones de relaciones sociales establecidas primariamente por la acción humana desde su trabajo:

El paisaje es finalmente biografía, es decir, historia personal... El trabajo, las acciones colectivas y la vida cotidiana... van construyendo socialmente el paisaje. Se puede postular que no van construyendo a largo plazo. Como el paisaje se manifiesta geográficamente, los cambios que acaecen en su apariencia a veces concurren a lo largo de períodos muy largos. Puede ocurrir, claro está que fenómenos ya sea de la naturaleza 0 del desarrollo social, provoquen cambios bruscos del paisaje (Cordero, 2012: 7).

A partir de esta cita, se plasma el concepto de captar la idea biográfica por medio del relato de vida, sugerido en la metodología. Sin embargo, pese al interés biográfico, lo medular es buscar en dichas biografías, filtradas por el eje étnico, los procesos de producción y producción paisajística, que las personas quienes accedieron a reconstruir sus relatos, detectan de su memoria social.

\section{PAISAJE Y TURISMO}

La reflexión anterior tiene que matizarse desde la perspectiva temática del proyecto de investigación, donde el peso de análisis tiene al turismo como eje articular fundamental. El turismo se establece como la actividad socio-económica que se ancla con los recursos físico-sociales de espacios geográficos usados temporalmente por una variedad de personas en calidad de recreación para unos y trabajo para otros. En este sentido, desde la segunda mitad del siglo xx, el desarrollo de la actividad turística está asociado a los patrones de desarrollo y lógica capitalista:

De modo que se puede suponer que la historia del turismo en el seno de la sociedad capitalista, empieza como una actividad que es posible dado un mayor desarrollo de los servicios en particular del transporte $y$ de los alojamientos, pero presumiblemente, en lo que tiene que ver con la naturaleza social del turismo, la posibilidad de su disfrute estaba principalmente limitada a las clases altas de la sociedad (Cordero, 2004: 18).

Sin embargo, también el turismo se ha desarrollado a partir de los alcances de personas no ubicadas en un sector socio-económico alto. Sino, más bien se ha desarrollado en espacios donde el acceso no solamente no requiere de mucha inversión económica, sino también dentro de los confines nacionales.

Así, el turismo es una actividad que se ha dado en un contexto de acumulación y que ha tenido un importante acomodo estructural en la economía internacional a partir de los años 80 (Pérez, Andrade-Eekhoff, Bastos y Herradora, 2004). Donde es una de las "nuevas" dinámicas socio-ocupacionales que más ha captado trabajadores y modificado espacios territoriales. Además, el impacto en el paisaje fue basado en la construcción o re-construcción de escenarios paisajísticos bajo una escala y parámetros internacionales, no necesariamente compatibles con los espacios comunales y naturales. Desde las comunidades, pese a reconocer una condición de menoscabo natural/biótico, el tema económico $y$ de ingresos se presenta como prioritario, más allá del resguardo natural, como lo sería el caso del Barrio Pacuare en Limón, recientemente estudiado desde una óptica de opiniones y estructura ocupacional (Carballo, 2013).

El trabajo es un factor clave en la construcción y modificación de los espacios físicos y en este caso, el turismo como dinámica laboral, enlazado con los parámetros capitalistas, ha tendido a variar las miradas de las personas, generando razonamientos $y$ sentimientos que por medio del relato de vida se busca captar. En 
este sentido, se presenta el turismo como un factor clave que está asociado a la provincia de Limón en términos de factores de un supuesto desarrollo, pero que a su vez presenta contradicción entre dichas formas de desarrollo y problemas sociales en las localidades $y$ comunidades.

\section{ANÁLISIS Y RECONSTRUCCIÓN DE LOS PAISAJES DE LIMÓN}

De acuerdo a la delimitación metodológica de la técnica de relatos de vida (Bertaux, 2005), la reconstrucción de los relatos a partir del eje étnico se establecerá desde la niñez, la juventud $y$ la adultez/vejez. El objeto será explorar las variables de la matriz base (cuadro 2) y poder descomponerla para rescatar los aportes específicos según la forma expresiva que las personas consultadas señalaron. El material teórico funciona para realizar la lectura desde la mirada de impacto de las relaciones sociales en la variación y modificación en la construcción del entorno paisajístico.

\section{LA NIÑEZ: CONSTRUCCIÓN DE LA IDENTIDAD}

La niñez es un momento social fundamental en la construcción de identidad y en la asimilación de las experiencias de vida, incluida la asimilación paisajística. Lo que esta sección permite es acudir a los recuerdos de las personas por medio de sus relatos, haciendo énfasis en los elementos que marcaron su crecimiento $y$ que fueron significativos como elementos del entorno. Cuando se habla de construcción de identidad, no se está haciendo una reflexión en las estructuras psicológicas, sino se está hablando desde los elementos que en la niñez son recuperados en los relatos y que marcan la posibilidad de valorar, tanto lo relevante para la persona que genera el relato, así como, elementos que ayuden a recrear la vivencia del paisaje con sus características retomadas. A partir de ahí se optó por rescatar dos tipos de elementos. El primero responde a un rasgo cultural y el otro es un rasgo paisajístico-cultural. Aunque ambos están interrelacionados, la idea es poder concentrarse en la gama amplia del entorno de identidad y el segundo sería una acotación más directa sobre el paisaje.

TABLA 1

FRAGMENTOS DE LOS RELATOS PARA EL ANÁLISIS DE LA NIÑEZ

2013

RELATORES
CONSTRUCCIÓN IDENTIDAD CULTURAL Y PAISAJE
Rasgo cultural: "El paisaje cambió, es recrear lo que pasaba en esa estación. iJa! iY es en
todoodas las estaciones!! Pero la más famosa, la de Siquirres, ahí es donde hacían los... como
se llamaa papi, los "gretacake", que cosa ves después de 75 años, yo todavía pienso en inglés, los
"greatacake" es el que lo hacían con blanco y rosado. Cajetas con blanco y rosado, entonces sigue
"candy", yo no sé, es que es un "candy" especial muy de los negros, yo se alguien que tiene un
familiar que lo hacía, pero tienen que ir al de Siquirres".
Rasgo paisajístico-cultural:"Ninguna provincia ganaba el parque de Limón. ¡Ninguna! Vea no
había nada más bonito en Limón que el parque, una cosa que no existía, ese montón de tierreros,
ese montón de gente vaga, ese montón de gente bañándose en... ¿Cómo se llama eso donde está
el agua del parque? ¡En la fuente, eso era sagrado! Eso era sagrado, naaadie se bañaba en esa
fuente, después acuérdese yo no sé si eran los martes o los miércoles cuando la banda bajaba, eso
ya no se hace, iaii, que lindo vea!, venía la banda y todo el mundo con su cosa iban al quiosco del
parque y ahí daban. ¿Cómo se llama lo que dan las bandas? Una retreta, ya eso no se da, entonces
el paisaje cambió, esa belleza cambió".




\section{RELATORES CONSTRUCCIÓN IDENTIDAD CULTURAL Y PAISAJE}

Rasgo cultural:"Por ejemplo mi hermano aprendió primero a hablar "mekateliu" que español porque la señora que nos ayudaba en la casa solo le hablaba en inglés y se lo llevaba los sábados y los domingos sin tener porque a pasear con ella y mi hermanito estaba en Moín en la mesa de tragos dominical con todos los amigos negros sentado desde los dos años, era así pero por otro lado era un mundo terriblemente elitista, o sea yo participaba de los dos mundos lo cual fue muy interesante porque paralelamente durante mi primera infancia en Limón era absolutamente elitista o sea había la elite que eran los empleados de la bananera, tanto los norteamericanos como los criollos que vivían en la zona que gozaban de una serie de prerrogativas muy especiales, al club Miramar no entraba un negro ni un chino, o sea era una época de mucho racismo pero por suerte yo me crie en el seno de una familia muy de mente abierta, que eran bueno como te conté mi madre totalmente integrada al mundo del colegio donde ella daba clases

A. Salaverry donde sí había profesores negros".

Rasgo paisajístico-cultural:"No, el parque estaría aquí, aquí estaba el club Miramar y el parque era como una lengüetita, ahora hicieron una cosas espantosa(risas) y bueno todo ese mundo glamoroso además del club Miramar estaba El Banana Boat que estaba en la zona bananera y había ahí unos bailes y unas fiestas impresionantes, toda la época de, del carnaval o del 12 de octubre por ahí, me trajeron fotos de una tía que se acaba de morir y hay algunas fotos de los 50 creo y de los bailes de disfraces que hacían porque siempre el baile tradicional del 12 de octubre era un baile de disfraces, entonces ahí se siente la elegancia, los que no llegaban disfrazados llegaban de traje con corbata, por ahí tengo que no la encontré una foto de los profesores del colegio también todos de saco y corbata elegantísimos siempre llegaban a dar clases así, a mí me tocó ver a los profesores de secundaria dar clases así y en la época de mi abuelo que por ahí había fotos también no solo era saco y corbata sino que chaleco y sombrero".

Rasgo Cultural: "Tenía novia si pero yo venía primero, cuando yo salía de universidad es que ella entra universidad cuando ella salir ya ella viene para acá... Yo estudió física matemática, China sur. Es una historia, en esa época China lo que muy pobre y mucha presión de políticos de ese tiempo, no hay nada de libertad y sobre esa razón ( se viene a Costa Rica), ahora ha cambiado montones... Es que en esa época en Limón hay una época. Estaban vendiendo propiedades están baratos entonces yo lo veo muy bien ubicado pero está muy abandonado entonces tuve a una como se llama negociación años 90 con ellos pero ellos no quieren vender, no quiere bajar nada ni siquiera bajar ni un centavo me dijo (risas) ok eso que pasó luego viene el terremoto entonces los señores estaban asustados y dice que porque no lo ha vendido y yo que dicha no lo compre, el tiempo se pasa y en el año 92 ellos me volver a buscar con eso, con eso citación no consiguieron buen, como se llama un buen precio".

O. Zen

Rasgo paisajístico-cultural: "En las playas no ha cambiado mucho pero hay un gran cambio este Parque Vargas, eso cambió por dos partes, uno por terremoto, otro parte es por descuido... Un ejemplo antes de terremoto eso parque llena de animales, todo tipos perezosos,... eh, mari, mariposas, los pajaritos, todo tipos, yo he visto una lechuza blanca que parada como 80 centímetros de altura fue aquí increíble, después de terremoto un año después comenzó cayendo árboles entonces yo fui a municipalidad entonces tuvo yo fui a municipalidad $y$ dice que el primero que cae ten cuidado se va a caer todo, tienen que hacer un estudio como a cantante árboles porque sin eso árboles sin animales, ellos me vieron como un loco, que tiene que ver con usted, que importa uno, eso pienso yo por eso se llama descuido es punto, porque ellos nadie iba a preguntar porque están cayendo árboles y cuando esos árboles unos cuatro, cinco, seis de grandes todo se cayó ahí se todos de animales".

Fuente: Elaboración desde las transcripciones de los relatos, 2013. 
ANÁLISIS DE LA CONSTRUCCIÓN ÉTNICA: CULTURALIDAD Y PAISAJE

Los distintos narradores mostraron un énfasis en la "belleza" del pasado limonense, donde el Parque Vargas capta una primacía fundamental. En este sentido, se hace énfasis en la centralidad de Limón como bello y agradable para una presunta convivencia, es un rasgo cultural que hoy se debate con el "abandono" y la despreocupación. Un peso simbólico clave es lo colorido de esa reconstrucción del pasado. Las dos narradoras hacen un significativo énfasis en la exposición de la vida principalmente por medio de la exhibición colorida, en las vestimentas, en el mismo Parque Vargas, en las comidas. Posteriormente en las narraciones, el colorido empieza a matizarse, dejando mostrar una versión mayoritariamente de tonalidades grises $y$ es de esa escala de grises con las que se reconstruye el paisaje actual. Además de lo colorido de ese Limón rememorado, el sonido y los sabores son expuestos en calidad de exuberancia. El filtro del recuerdo y la niñez de estos narradores, hoy en su etapa de madurez y vejez, descubre una espectacularidad de un Limón cargado de jolgorio, donde la diversión, la diversidad y los contrastes son parte fundantes de lo que se podría llamar una etnicidad, construida en las formas de recordar de los narradores. Puntualmente, la culturalidad limonense se amarra según los tres relatos, principalmente el de las dos mujeres, a partir de contrastes, donde el colorido es muestra de la vivacidad con la que caracterizan dimensiones de vida de la provincia en un pasado biográfico.

Se presenta un Limón no negro, sino diverso, multicolor. En la diversidad, si bien la negritud cumple un rol fuerte en términos culturales, las desigualdades también son parte del complejo sistema social, pero que pese existir, los relatos también señalan matices respecto a la forma de operar. Los narradores vivieron en un Limón que recuerdan cargado culturalmente con diferencias y con espacios de belleza natural. Ambos presentes en una reflexión desde la elegancia y que actualmente ha "perdido" su "brillo" y su estilo. Las razones que se dan se profundizan en el siguiente apartado.

\section{LA JUVENTUD: TRABAJO, TURISMO Y SAN JOSÉ}

En la etapa de la juventud, dos de las acciones más importantes que se recuerdan en relación con el interés del artículo, es el inicio de la vinculación con la dimensión laboral y la movilización; donde San José se convierte en un importante espacio de captación laboral de gran parte de la población de las provincias del país. En este sentido, la vivencia de la juventud se ve matizada por la apertura e incorporación de nuevos espacios simbólicos y físicos en la experiencia paisajística de las personas. En trayectos $y$ en dimensiones laborales marcadas desde la culturalidad, el espacio físico y el desarrollo turístico, como lo han sido las zonas costeras del país. 
TABLA 2

FRAGMENTOS DE LOS RELATOS PARA EL ANÁLISIS DE LA JUVENTUD 2013

\begin{tabular}{ll} 
RELATORES & TRABAJO Y TURISMO \\
\hline & "iEl turismo, claro el turismo! El turismo \\
& desmedido, yo no sé si uso bien la palabra \\
& desmedida, es el turismo, vea personalmente \\
& no me crea, creo que el Tortuguero debió \\
& ser... como se llama eso, en inglés se \\
& dice shrine, shrine es algo como sagrado, \\
& entonces debería ser como un shrine para las \\
& tortugas, jun santuario! Jaaamás debió ser \\
& para turistas, vea papi pero para hacer esto \\
& vas a tener que ir a Tortuguero".
\end{tabular}
vas a tener que ir a Tortuguero".

\section{RELACIONES CON SAN JOSÉ}

“¿pero por qué cambiaron la construcción de las casas? Eso es importante vea le voy a explicar, en la construcción de las casas arriba estaba las casas pero arriba había una cocinita, abajo había un corredor y una cocina entonces cuando subía el río todo el mundo se iba para arriba, no había problemas, no había albergues. Te voy a contar algo que me contaron, me lo conto. Trudy Clark, algún momento tenés que hablarle a Trudita linda, porque ella lo vivió, me entiende, dice la gente de San José, el problema vienen con la gente que viene de allá y no respetan, que es que está bien que pase eso porque viene la gente $y$ le das colchones, le da esto, el otro y el otro entonces el paisaje cambia totalmente ¿Voy con usted?”.

“... de todo punto de vista eran, Limón era un gueto que no participaba de lo que significaba el resto del país, con esa invasión evidentemente las proporciones cambian y empiezan a dejar su impronta los recién llegados, sin el amor por un pasado que no es de ellos así que regresar a, recuperar $u$ otorgarle a estas nuevas personas su sentido de pertenencia yo creo que sería muy importante verdad, lograr que se sintieran limonenses en la dimensión de todo lo que significa ser limonense, que significan muchas cosas verdad no es solamente el tema del carnaval o cosas así muy superficiales, Limón es de una riqueza impresionante si se logra mantener $y$ fortalecer toda la herencia a nivel de alimentación, a nivel de costumbres, a nivel musical, ahí hay una capacidad impresionante, latente...".

\begin{abstract}
"No se tal vez por tiempo, tal vez se va a seguir es que como si sigue es que se acuerda Limón hay un proyecto este de 30:55 muelle de alemán, muelle turístico, eso es muy buena proyecto pero lo rechazaron... se acuerda, es que yo he andado en muchos países por todo del caribes, los ambientes, los paisajes parecido pero hay mucha diferencia es que cuando hay un lugar tiene muelle de turismo alrededor de ello llegan mucho turistas".
\end{abstract} O. Zen
"No se aquí es que, en ese país cualquiera proyecto pueden pasar como 10, 15, 20 años verdad y yo viendo es cosa es que mientras está discutiendo en 10 años no sé cuánta plata desperdiciado mientras los políticos están discutiendo pero gasto nunca ha parado, finalmente cualquiera proyecto subió costo una, dos veces, cinco veces".

Fuente: Elaboración desde las transcripciones de los relatos, 2013. 
A partir del análisis de la etapa del vínculo laboral y josefino, el peso del turismo de Limón ha sido significativo, pero las expresiones son contrarias. Por un lado, el turismo es un mecanismo fundamental, mientras que por otro, es una forma destructiva. Sin profundizar en los posibles modelos de desarrollo de un espacio o formas turísticas, la lógica del "progreso" es la que predominó en la modernización técnica de Limón. En buena medida, según lo que se desprende de los relatos, la razón de ese incremento de peso del turismo es la vinculación con el resto del país, pero en forma fundamental con San José y de ahí con el contexto global. Sin embargo, hay dos importantes consideraciones políticas que surgen. En el caso de la primera entrevista, "San José" es responsable del descuido de la provincia de Limón, mientras que el único entrevistado hombre, resalta la lentitud y pésimo desempeño político, tanto de los mismos limonenses como de los políticos nacionales en general.

Se puede observar la ambivalencia de las opiniones, donde convergen las ideas de progreso y destrucción, ambas vinculadas bajo el matiz de una actividad laboral que se ha convertido en símbolo económico de la provincia. Desde la teoría del paisaje, pero no completamente uniforme con ella, se está ante la existencia de más de un paisaje. En este caso, se podría ver dos paisajes; uno ligado con el descolorido nuevo entorno natural $y$ otro ligado con el "progreso" laboral que utiliza dicha naturalidad pero como entorno de trabajo. Con esto se señala las miradas, los intereses y el posicionamiento relativo de las personas respecto de lo que ven $y$ viven.

Es en la reconstrucción de la juventud donde los quiebres idealizados de las y él relator se rompen, o al menos se presentan como discusión. Estos dos paisajes que se superponen uno al otro, se muestran en contradicción y evidencian desde los relatos, el peso del trabajo y de las relaciones humanas en la reconstrucción del paisaje ampliado, sea este más o menos consciente. También se evidencian tres estados de la vinculación o lo que se podría llamar tres "paisajes deseados". Un paisaje de no explotación de lo natural: un paisaje "virgen", que sería el de la primera relatora; un paisaje de "equilibrio" y necesidad por parte de la segunda relatora y el último sería un paisaje "extensivo", es decir, de uso globalizado, en el caso del último relator. Cada "paisaje deseado"9 estaría mostrando su posición respecto al uso de lo natural y de quienes realizarían dicho uso, lo cual es una posición socio-política que se podría tentativamente señalar.

Si bien son "paisajes deseados", lo que se está señalando de fondo es que las miradas de los paisajes no son solo desde lo que viven, sino también de la reconstrucción de su pasado de base identitaria, para desplegarlo en soluciones latentes, en donde los mismos paisajes deseados son opiniones reproducidas en imágenes del uso y la construcción paisajística.

\section{ADULTEZ/VEJEZ: RECONSTRUCCIÓN DE LA IDENTIDAD, IMPACTO JOSEFINO Y NATURALEZA}

Las personas seleccionadas hablan reconstruyendo sus relatos desde un momento vivido, ubicados en una etapa adulta ( $y$ de vejez). La valoración de cambios desde su infancia y juventud permite acceder a ciertos elementos de su capacidad interpretativa, pero sobre todo sus formas valorativas del cambio. Así, dos temas que relucen en el escenario actual de las personas son el factor de la relación con San José - que viene desde la juventud-y el espacio turístico, sin dejar de lado la reelaboración de los valores que se han reconstruido hasta la fecha.

\footnotetext{
$9 \quad$ Esta reflexión analítica de la juventud también estaría operando en el caso de la adultez o vejez, ya que interviene en la construcción de una mirada crítica del entorno social que incluye a su vez el paisaje.
} 


\author{
TABLA 3 \\ FRAGMENTOS DE LOS RELATOS PARA EL ANÁLISIS DE LA ADULTEZ/VEJEZ \\ 2013
}

\begin{tabular}{|c|c|c|}
\hline RELATORES & IMPACTO JOSEFINO EN NATURALEZA & RECONSTRUCCIÓN DE LA IDENTIDAD \\
\hline J. Sawyers & $\begin{array}{l}\text { "Yo lo quiero enfocar desde el punto de } \\
\text { vista negro, porque no quiero generalizar, } \\
\text { vea resulta que primero tenemos que ir al } \\
\text { problema del país, nos guste o no nos guste } \\
\text { somos discriminados, es la verdad nadie quiere } \\
\text { que diga eso pero es la verdad, no tenemos } \\
\text { oportunidades. (...) yo no volví a nada del INAMU } \\
\text { porque hablan y hablan y hablan llevan añales } \\
\text { hablando, hicieron algo muy bonito cuando } \\
\text { hicieron lo de la afro-descendencia viste lo que } \\
\text { hicieron pero estaba bonitilla yo no volví más } \\
\text { no van, Mauren está tratando pero, ok. Entonces } \\
\text { esta es la parte fea que tal vez no le guste, hay } \\
\text { una argollita hay una argollita, la argollita no } \\
\text { tiene poder económico pero de alguna manera } \\
\text { tiene un poquito de poder político, pero no es } \\
\text { mucho, cuando uno tiene poder político uno } \\
\text { cambia las cosas ellos no pueden cambiar } \\
\text { nada entonces para mí, mi percepción es que } \\
\text { tienen que despertarse pero si me dices, si } \\
\text { me dices y como son como madres ay sí, son } \\
\text { excepcionales". }\end{array}$ & $\begin{array}{l}\text { “...tendrías que ir más allá, ok vea entonces } \\
\text { vámonos un poquito más allá. Bueno vea papi, } \\
\text { vea mi amor hay que ir atrás, atrás, atrás, } \\
\text { atrás estamos hablando de 1898, pero atrás } \\
\text { atrás, cuando llegan los primeros abuelos, } \\
\text { los primero abuelos vienen con toda una } \\
\text { tradición inglesa con la cuadrilla. Por cierto } \\
\text { te quiero contar una parte bonita, con ese } \\
\text { conservatorio que hizo CunLimón se pudo } \\
\text { recatar la música de la cuadrilla y ya lo tocan. } \\
\text { Resulta que yo tenía los discos, mentira yo } \\
\text { tenía cassettes robados de las viejitas, pero } \\
\text { como yo no soy música yo no sabía entonces } \\
\text { viene la oEA y me manda una señora de } \\
\text { Colombia que se llamaba Gladys entonces } \\
\text { nosotros le tarareamos a Gladys tararrararara } \\
\text { y ella se sentaba y todo lo puso en música } \\
\text { escrito (aplaude). Sí, claro ella lo hizo conmigo } \\
\text { en el Cli cuando yo trabajaba en el Cli, } \\
\text { pero yo no sé hacer eso a ella la mandaron, } \\
\text { nosotros tratamos a como hubo lugar de } \\
\text { que el viejito. jEl único viejito! Que tocaba la } \\
\text { flauta, que llevaba el paso de la cuadrilla... y } \\
\text { no lo logramos se murió con él, viera como lo } \\
\text { tratamos y se murió, de todos modos lo hemos } \\
\text { salvado pero no como es exactamente porque } \\
\text { también tenemos un cassette". }\end{array}$ \\
\hline A. Salaverry & $\begin{array}{l}\text { "Bueno yo creo que volvemos a lo mismo } \\
\text { esa inmigración masiva de gente del interior } \\
\text { primero cambio los porcentajes, Limón tenía } \\
\text { un } 80 \% \text { de población negra y un } 20 \% \text { de } \\
\text { población blanca eso se está revirtiendo pero } \\
\text { terriblemente yo creo que con suerte habrá } \\
\text { un } 30 \% \text { de población negra ahora contra } \\
\text { toda una eeh, una cantidad de población muy } \\
\text { fuerte, con costumbres, con apreciaciones, } \\
\text { con eeh conceptos pues muy distintos verdad, } \\
\text { el hecho de que fuese un lugar tan cerrado } \\
\text { geográficamente permitía que hubiese una } \\
\text { identidad muy acentuada muy particular... } \\
\text { Este incluso hubo otro proyecto al lado de playa } \\
\text { bonita que fue un parque que eso fue una idea } \\
\text { inicial de mi madre y la desarrollo doña Estrella } \\
\text { eeh Zeledón de Carazo, doña Estrella vivió su } \\
\text { infancia en Limón la mamá de ella fue maestra } \\
\text { en Limón ella estaba muy vinculada hizo ese } \\
\text { parque que era una belleza porque era una zona } \\
\text { virgen nada mas con senderitos y eso se dejó, se } \\
\text { perdió yo no sé qué se hizo ahora no hay nada } \\
\text { ahí ahorita talan todo y lo destrozan verdad". }\end{array}$ & $\begin{array}{l}\text { "Limón se ha transformado ahora con } \\
\text { una visión un poquito limitante en el } \\
\text { Limón de la población negra y se está } \\
\text { olvidando todo el aporte de la población } \\
\text { blanca que fue también, muy importante } \\
\text { en la construcción de la idiosincrasia de } \\
\text { lo que es hoy Limón este, ahí hubo mucha } \\
\text { gente importante que fue consolidando lo } \\
\text { que es hoy Limón, dentro de las historias } \\
\text { familiares por ejemplo don Mario Castro } \\
\text { que es el papá de este pintor de Mario } \\
\text { Gerardo Castro, él trabajaba en el banco } \\
\text { de sangre, era microbiólogo y trabajaba } \\
\text { en el hospital y él es el primero que } \\
\text { hace un banco de sangre en Limón y el } \\
\text { primero que se dedica a investigar lo que } \\
\text { significaban los grupos porque antes le } \\
\text { ponían una transfusión de lo que fuera, de } \\
\text { lo que cayera, de lo que estuviera a mano, } \\
\text { este hace todo un trabajo para lograr } \\
\text { tener un banco de sangre en Limón, el } \\
\text { marido de mi madre Rómulo Salas } \\
\text { Guevara que la sede de la ucr en Limón } \\
\text { lleva el nombre de él". }\end{array}$ \\
\hline
\end{tabular}


"El paisaje está bien digamos que claro uno ya tiene algo de estructura de económico verdad eso en la vida siempre es muy importante si uno se está muriendo de hambre no va a sentir que este paisaje que está lindo. Pero para mí Limón es muy lindo todo cerca, todo fácil y tranquilidad es mejor que San José, inseguridad por todo lado, por todo país pero no es tan grave como prensa que habla... En las playas no ha cambiado mucho pero hay un gran cambio este Parque Vargas, eso cambió por dos partes, uno por terremoto, otro parte es por descuido".
"Como explicar esa parte, parece que cada día la gente más violentos, malcriados, falta respeto... Cuando llegamos a Costa Rica esa gente de ese país muy amable, es increíble pero ha cambiado muchísimo... Poco a poco, yo creo que aquí andan muy malos políticos... Políticos es decir más digamos políticos en general no no por un cantón o es decir general, pero eso no es una persona o un grupo de gente se puede controlar o cambiar ósea es una mierda no sé hasta dónde vamos a cuando llegar... Para poner un poquito más practicar más socado porque los ticos muy inteligentes pero usted sabe que matemática o química o ese biología necesitan mucho estudio, necesitan mucho practicar ese si faltaba pero esta vez porque acostumbra, uno no quiere los jóvenes que quitando presión como aquí no hay mucha competencia, en China mucha competencia sobre eso, todo mundo como mi hijo cuando anda en China estudiando del idioma chino dice vea dice que solo ve compañeros todo mundo como todos los días como tan preocupados".

Fuente: Elaboración desde las transcripciones de los relatos, 2013.

Desde el análisis de la re-construcción cultural, los dos relatos de las mujeres coinciden en un deterioro general $y$ dentro de este, la naturaleza en la que se enmarca Limón: perdió color y vivacidad, podría ser una conclusión. Sin embargo, estas visiones de deterioro contrastan con las miradas de progreso, particularmente en el plano laboral y educacional, además del desarrollo de una visión política y de progreso mucho más estructurada en los años 60 y 70. En el caso del único relator hombre, que llega en los 80 a Costa Rica desde China, la visión de la naturaleza no es tan precisa, lo que expone con más fuerza es el tema de las actitudes y lo laboral. Esto está relacionado con su concepción laboral y sus consideraciones desde un esfuerzo personal, de adaptación cultural y de necesidades mucho más explícitas en sus relatos.

La versión de las relatoras conjuga la idea de "rescatar", con la idea de la mirada parcializada - "limitación" — de un homogéneo Limón (un "Limón negro"). Ambas categorías marcan un acercamiento paisajístico que envuelve la reflexión bajo un recuerdo mítico y añorado, así como recela la ausencia de la pluralidad social $y$ colorida de dicho pasado. Se sugiere una idea de identidad en "descomposición" o asediada. En estos sentidos, parece que surge la idea de que lo cultural o lo étnico es estático y que las mutaciones o cambios, no son propios de las dinámicas culturales, sino que el cambio se lee bajo una mirada de descomposición de la unidad étnica casi idealizada del primer relato. No obstante, la idea de progreso y desarrollo está marcada en la segunda relatora, donde la vinculación con el centro capitalino (ampliado al área metropolitana) está, tanto del lado de las mejorías como también con la descomposición colorida del Limón plural.

El relator hace énfasis en las cualidades individuales de actitud $y$ esfuerzo que estaban presentes en los extractos de la sección anterior con la juventud. Es importante que el énfasis general que recoge sea la capacidad y esfuerzo asociados a lo personal, en donde lo paisajístico está concentrado en una mirada principalmente 
idealizada de que es aprovechable como oportunidad de avanzar, en este caso, las playas.

En términos generales $y$ sin una profundización extensa, se sugiere que la reconstrucción de la identidad se ha hecho desde una lectura del deterioro del mismo paisaje. Si bien existen otras formas de analizar el fenómeno de la reconstrucción identitario, en el caso de hacerlo desde lo paisajístico asociado a lo étnico permite incorporar la idea de que lo que se mira (con los ojos y la imaginación) se desarrolla desde la mirada que se tiene del entorno. Es decir, la idea de descomposición o de un "progreso" con consecuencias degradantes del ambiente, es al mismo tiempo un indicador visual de la degradación social y de la descomposición de los "valores" étnicos propios de las personas limonenses. En los relatos se desprende la "necesaria" vinculación con el resto del país, especialmente con San José, pero al mismo tiempo se critica esta conexión y se expone una de las principales causantes de la descomposición y descolorido de la provincia.

\section{CONCLUSIONES: PAISAJES Y CONFLICTOS}

Los tres estadios sociales (niñez-juventud-adultez) permiten abordar desde una visión de proceso, las valoraciones de las personas a partir de sus relatos de vida. Al buscar reconstruir esas miradas sobre el paisaje como elementos socio-vivencial, se ha profundizado, con reservas y limitaciones, en las miradas sobre el entorno paisajístico, sus modificaciones y la relación entre personas, relaciones sociales y entorno natural.

Una de las principales conclusiones es la visión que se tiene sobre el paisaje como un espacio de "fondo", pero poco a poco pierde su entorno de "fondo" en el momento en que se matiza y se relaciona con lo vivido; es decir, la visión de lo hermoso eminentemente visual del paisaje, pasa a una vivencia y de ahí a una visión de relación con el contexto. Uno de los casos más representativos es la visión del color expuesto desde la niñez en las dos relatoras que crecieron en los escenarios sociales de Limón. En este sentido, la visión actual de lo paisajístico limonense pasa más por un claro oscuro, por un juego de luz y sombras, más que por el plural caudal colorido de la vida rememorada de las relatoras. Un elemento que reluce es el factor de la fuerte población negra, fuerte en el sentido de proporción, así como en el posicionamiento cultural y que con el tiempo ha mermado en una reconstitución diversa, que desde una cierta lectura puede verse como pluralidad, pero en otra visión como interferencia a un supuesto Limón "puro" de bases negras fundamentalmente. Se entra en el debate entre si es ahora más plural que antes, pero queda de fondo que el tema de la pluralidad y la diversidad es un tema medular en la discursividad sobre las miradas paisajísticas de los limonenses.

Esta decoloración se puede interpretar como una de las lecturas que hacen las y él entrevistado de la relación entre turismo, vínculos laborales y con San José, donde una de las consecuencias más reconocibles es el deterioro biótico, es decir, el deterioro del paisaje natural, pero que todavía se concentra en elementos puntuales como playas o sitios categorizados como turísticos. La reflexión que hicieron sobre el paisaje fue ampliándose debido a la incorporación de elementos culturales y que a su vez daban matices que fueron identificando como propios de una pluralidad colorida socio-cultural. Una de las valoraciones que surge de estas relaciones y miradas es la consecuencia negativa de la destrucción de la naturaleza, aun cuando haya producido fuentes de trabajo ${ }^{10}$.

La reconstrucción del paisaje se hizo apelando a una vida desarrollada de las y él relator, ya que los tres superaban la edad de los 60 años. En este sentido, cada uno hizo una reconstrucción de cómo debía funcionar la relación entre turismo y naturaleza, esto con la idea de resguardar la belleza rememorada de lo natural de su infancia. De ahí la idea de utilizar el término de "paisaje deseado" que eran: a)

10 Esto viene siendo la siguiente paradoja: más turismo se ha traducido en destrucción de los recursos naturales, que es una de las razones por las cuales el turismo en esa zona fue en primer lugar explotado. No es parte de este artículo analizar de fondo esta situación compleja, solo mencionar que es parte de los elementos que están incrustados en la reconstrucción del paisaje limonense. 
paisaje "virgen", b) paisaje de "equilibrio" y c) paisaje "extensivo". Con este criterio se resume la concepción de que cada relato entraña una forma distinta del "deber ser" de la relación laboral; sin embargo, ese "deber ser" de cada relato busca que lo natural se recupere o mantenga su color, tanto natural como se podría presuponer, la pluralidad étnico-cultural. Además, lo económico-político es un elemento que recorre los relatos de manera sombreada, es decir, como un elemento indiferenciado en la mayoría de los casos, donde forman parte de un contexto político poco profundizado, por razones de los mismos relatos como por la dinámica de la técnica de relato aplicada, pero que sí es mencionado en función de su conexión con el tema del desarrollo como discurso hegemónico.

Una última conclusión, esta vez reflexionando de manera general, señala que la lógica capitalista de incremento de la producción y de los servicios -incluyendo el turismo - tiene, como desde el entorno teórico se apuntaba, un importante peso en la reconstrucción del paisaje, ya que las formas que el modelo de producción presiona sobre las formas relacionales en el trabajo $y$ el uso extensivo de los recursos naturales, han modificado las formas de mirar no solo lo natural, sino también las mismas relaciones cotidianas de las personas, como los relatos muestran. Se encuentra un escenario étnico marcado fuertemente bajo una prerrogativa de belleza y colorido - natural y cultural - que era marca fundamental de la construcción identitaria y que el deterioro o la modificación significativa por entes principalmente externos - un San José de comercio mundial- ha establecido en una escala de grises, donde aventurando una metáfora para entender el "sentir" de los relatos — particularmente, el de las relatoras - ha venido destiñendo la compleja vida cultural.
BIBLIOGRAFÍA

LIBROS

Bertaux, Daniel. Los relatos de vida. Perspectiva etnosociológica. España: Ediciones Bellaterra, 2005.

Cordero, Allen. Nuevos ejes de acumulación y naturaleza: el caso del turismo. San José, Costa Rica: Facultad Latinoamericana de Ciencias SocialesFLACSO, 2004.

Heidegger, Martín. Ser y tiempo. Santiago, Chile: Editorial Universitaria, 2002.

Pérez Sáinz, Juan Pablo; Andrade-Eekhoff, Katharine; Bastos, Santiago y Herradora, Michael. La estructura social ante la globalización. Procesos de reordenamiento social en Centroamérica durante la década de los 90. San José, Costa Rica: Facultad Latinoamericana de Ciencias Sociales-flacso, Organización de las Naciones Unidas-onu y Comisión Económica para América Latina y el Caribe-cEpal, 2004.

Roger, Alain. Breve Tratado del Paisaje. Madrid, España: Editorial Biblioteca Nueva, 2007.

Savater, Fernando. La aventura de pensar. Barcelona, España: Editorial DeBolsillo, 2011.

Touraine, Alain. ¿Qué es la democracia? México DF, México: Fondo de Cultura Económica, Sección Sociología, 2006.

Watsuji, Tetsuro (1935). Antropología del paisaje. Climas, cultura, y religiones. Salamanca, España: Ediciones sigueme Salamanca, 2006.

Weber, Max. Economía y sociedad. Esbozo de sociología comprensiva. México DF, México: Fondo de Cultura Económica, 2008. 
PUBLICACIONES PERIÓDICAS

Carballo, Pablo. "Turismo en Limón: datos y elementos de análisis sobre la dinámica de las actividades laborales. El caso del Barrio Pacuare ubicado en el cantón central”. Revista de Ciencias Sociales 142. San José, Costa Rica. Universidad de Costa Rica, 2013: 13-29.

Moreno, Isidoro. "Etnicidad, conciencia de etnicidad y movimientos nacionalistas: aproximación al caso andaluz". Revista de Estudios Andaluces 5. 1985: 13-38. En <http://institucional.us.es/revistas/ andaluces/5/art_1.pdf> [consultado el 09 de setiembre de 2013].

OTROS

Cordero, Allen. "Paisajes y relatos de vida. (Apuntes para el marco teórico-metodológico del proyecto Centros Históricos del Turismo en fase de ampliación)". Universidad de Costa Rica. Documento inédito, 2012.

Fecha de ingreso: 22/01/2014 Fecha de aprobación: 20/11/2014 
